There were substantial differences concerning localization of the lesions: in $\mathrm{OCI}$, ventral localization was recorded in $96 \%$ of the cases for osteitis, in $100 \%$ for fatty degeneration, and in $96 \%$ for sclerosis, while in axSpA, osteitis was preferentially localised in the ventral part only in $29 \%$ of the cases, fatty degeneration in $25 \%$, sclerosis in $29 \%$. Ankylosis and erosions were localised in the mid part in almost all cases.

Abstract FRI0173 - Table 1. Active and chronic lesions of the sacroiliac joints as detected by $\mathrm{MRI}$ in patients with osteitis condensans ilii $(\mathrm{OCl})$ and with axial spondyloarthritis (axSpA).

\begin{tabular}{|c|c|c|c|}
\hline MRI changes & OCl & axSpA & p-value ${ }^{+x}$ \\
\hline & $N=27^{\star \star *}$ & $N=27$ & \\
\hline Osteitis score (0-24), mean $\pm \mathrm{SD}$ & $3.6 \pm 2.3$ & $4.4 \pm 4.1$ & 0.89 \\
\hline Osteitis present, $\mathbf{n}(\%)$ & $25(96.2)$ & $23(85.2)$ & 0.351 \\
\hline $\begin{array}{l}\text { Fatty degeneration score }(0-24) \text {, } \\
\text { mean } \pm S D\end{array}$ & $2.0 \pm 2.3$ & $4.5 \pm 6.7$ & 0.001 \\
\hline Fatty degeneration present, $\mathbf{n}(\%)$ & $14(51.9)$ & $20(74.1)$ & 0.158 \\
\hline Erosions score $(0-6)$, mean \pm SD & $0.2 \pm 0.4$ & $3.0 \pm 2.3$ & $<0.001$ \\
\hline Erosions present", n (\%) & $2(7.4 \%)$ & $18(66.7 \%)$ & $<0.001$ \\
\hline Ankylosis score $(0-2)$, mean \pm SD & 0 & $0.3 \pm 0.7$ & 0.040 \\
\hline Ankylosis present", $\mathbf{n}(\%)$ & $0(0)$ & $4(14.8 \%)$ & 0.111 \\
\hline Sclerosis score (0-2), mean \pm SD & $1.4 \pm 0.6$ & $1.0 \pm 0.8$ & 0.055 \\
\hline Sclerosis present ${ }^{*}, \mathrm{n}(\%)$ & $24(88.9)$ & $19(70.4)$ & 0.175 \\
\hline
\end{tabular}

The absolute lesion scores represent mean values of 3 readers. Lesions were considered to be present if the corresponding score was $\geq 1$ in the opinion of at least two readers.

${ }^{\star} \mathrm{N}=26$ for osteitis. ${ }^{\star \star}$ Derived from the Mann-Whitney U-test for the scale variable or from the Fisher's exact test for the categorical variables.

Conclusions: $\mathrm{MRI}$ of sacroiliac joints in $\mathrm{OCl}$ is characterised by preferential ventral localization of lesions (osteitis, fatty degeneration, sclerosis), absence of ankylosis and absence of extended erosive changes. Such a findings constellation should be taken into account as suggestive of $\mathrm{OCI}$ for the differential diagnosis of ax SpA in clinical practice.

Disclosure of Interest: None declared

DOI: 10.1136/annrheumdis-2018-eular.2574

\section{FRI0174 SPINAL RADIOGRAPHIC PROGRESSION IN EARLY AXIAL SPA: 5-YEAR DATA FROM THE DESIR COHORT}

S. Ramiro ${ }^{1}$, D. van der Heijde ${ }^{1}$, A. Sepriano ${ }^{1}$, M. van Lunteren ${ }^{1}$, A. Molto ${ }^{2}$, A. Feydy ${ }^{2}$, M.A. D' Agostino ${ }^{3}$, D. Loeuille ${ }^{4}$, M. Dougados ${ }^{2}$, M. Reijnierse ${ }^{1}$, P. Claudepièrre ${ }^{5} .{ }^{1}$ Leiden University Medical Center, Leiden, Netherlands; ${ }^{2}$ Paris Descartes University, ${ }^{3}$ Université Versailles-Saint Quentin en Yvelines BoulogneBillancour, Paris; ${ }^{4}$ University of Nancy, Nancy; ${ }^{5}$ Université Paris Est Créteil, Créteil, France

Background: Spinal radiographic progression has been investigated in patients (pts) with r-axSpA, but not yet as thoroughly in early axSpA.

Objectives: To analyse the progression of spinal radiographic damage in pts with early axSpA.

Methods: Five-year follow-up data (baseline, 2 and 5 years) from the DESIR cohort, including pts with early axSpA, were used. Cervical and lumbar radiographs were centrally and independently scored by 3 readers (averaged scores), blind for chronological order and clinical characteristics, according to the mSASSS (0-72). Change scores for all available intervals were calculated. Pts were included if they had $\geq 1$ mSASSS interval available $(0-2 \mathrm{y}, 2-5$ y or $0-5 \mathrm{y})$. The development of new syndesmophytes (2 out of 3 readers) was calculated as a net change, i.e. subtracting the number of pts in whom an existing syndesmophyte ('noise') is no longer reported from those with a new syndesmophyte ('true progression'), divided by all pts. Two- and 5 year mSASSS progression and development of new syndesmophytes were assessed in each subgroup of pts according to the ASAS axSpA criteria and its arms at baseline (see figure 1). In addition, pts were grouped according to the fulfilment of mNYC and also to the presence of baseline syndesmophytes.

Results: In total, 549 pts (mean age 34 (SD 9) years, $46 \%$ males, $63 \%$ fulfilling ASAS axSpA criteria, baseline mSASSS 0.46 (1.54)) were included. Thirty-eight pts $(7 \%)$ showed syndesmophytes at baseline, $42 \%$ of which were ASAS axSpA criteria negative. Mean mSASSS progression was $0.15(0.94)$ at 2 years and 0.42 (1.77) at 5 years. $18 \%$ of the pts fulfilling the ASAS axSpA criteria showed a 5 year positive mSASSS change $(>0)$, compared to $30 \%$ in those not fulfilling the criteria (figure 1). $26 \%$ of the pts fulfilling the imaging arm had a positive change: highest positive change in MRI-mNYC+ (34\%), followed by MRI+mNYC+(29\%) and lastly MRI+mNYC- (23\%). Mean mSASSS progression was highest in the mNYC +MRI + group (1.34 (3.98)). Eleven percent of the pts fulfilling only the clinical arm of the ASAS criteria had a positive change in mSASSS at 5 years, mean change of 0.13 (0.65). Pts with baseline syndesmophytes (across all subgroups) had the highest progression: 2.69 (5.02) mSASSS-units. At 5 years, $7 \%$ of all pts had a net change of any new syndesmophyte; this was $6 \%$ for ASAS+pts, $9 \%$ for ASAS-, $10 \%$ for pts fulfilling the imaging arm ( $18 \%$ for $\mathrm{mNYC}+\mathrm{MRI}+)$ and $3 \%$ for pts fulfilling the clinical arm only. Seventeen percent of the mNYC +pts had a net change in new syndesmophytes as well as $42 \%$ of the pts with baseline syndesmophytes.

5-year radiographic progression: categories of mSASSS progression

\begin{tabular}{|c|c|c|c|c|c|}
\hline \multicolumn{6}{|c|}{ 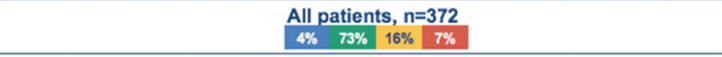 } \\
\hline \multicolumn{5}{|c|}{$\begin{array}{c}\text { ASAS +, } n=242 \\
4 \% \quad 78 \% \quad 11 \% \quad 7 \% \\
\end{array}$} & 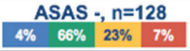 \\
\hline \multicolumn{3}{|c|}{ 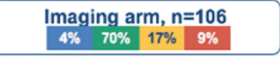 } & \multicolumn{2}{|c|}{$\begin{array}{l}\text { Clinical arm, } n=136 \\
\begin{array}{|l|l|l|}4 \% \% & 7 \% \\
\end{array}\end{array}$} & \\
\hline $\begin{array}{l}\text { MRI- } \\
\text { NYC+ }\end{array}$ & $\begin{array}{l}\mathrm{MRI+} \\
\mathrm{NYC}+\end{array}$ & $\begin{array}{l}\text { MRI+ } \\
\text { NYC- }\end{array}$ & CRP+ & CRP. & \\
\hline $0 \% \quad 67 \%$ & $6 \% \quad 67 \%$ & $4 \% \quad 73 \%$ & $7 \% \quad 89 \%$ & $4 \% 83 \%$ & \\
\hline $\begin{array}{c}27 \% \quad 7 \% \\
\mathrm{n}=15\end{array}$ & $\begin{array}{l}12 \% \quad 15 \% \\
n=32\end{array}$ & $16 \%$ & $4 \% \quad 0 \%$ & $7 \% \quad 6 \%$ & \\
\hline \multirow{2}{*}{\multicolumn{2}{|c|}{ 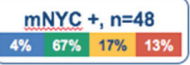 }} & \multicolumn{4}{|c|}{$m N Y C \cdot, n=319$} \\
\hline & & & & $\begin{array}{llll}4 \% & 75 \% & 15\end{array}$ & $6 \%$ \\
\hline $\begin{array}{l}<0 \text { mSASS } \\
\text { units }\end{array}$ & $\begin{array}{l}0 \mathrm{mSAS} \\
\text { unit }\end{array}$ & & $\begin{array}{l}8 \& 2 \\
\text { ss-units }\end{array}$ & $\begin{array}{l}\text { mSASSs- } \\
\text { units }\end{array}$ & \\
\hline
\end{tabular}

Abstract FRI0174 - Figure 1. Five-year mSASSS radiographic progression categories according to the subgroups of the ASAS criteria, arms of the ASAS criteria and fulfilment of $\mathrm{mNYC}$ at baseline.

The totals of some groups are higher than the sum of the subgroups due to miss ing data not allowing to classify patients into the subgroups.

Conclusions: Spinal radiographic progression, though limited in early axSpA can be captured already at 2 years of follow-up. Progression is higher in pts fulfilling the mNYC and also in pts with baseline syndesmophytes. Almost half of the pts with early axSpA with a syndesmophyte at baseline develop further syndes mophytes over 5 years.

Disclosure of Interest: None declared

DOI: 10.1136/annrheumdis-2018-eular.2928

\section{FRI0175 RATES AND PREDICTORS OF RADIOGRAPHIC SACROILIITIS PROGRESSION AFTER CENTRAL READING IN PATIENTS WITH AXIAL SPONDYLOARTHRITIS FROM THE ASAS COHORT: A 5- YEAR FOLLOW-UP STUDY}

M. Protopopov ${ }^{1}$, F. Proft ${ }^{1}$, A. Sepriano ${ }^{2,3}$, R. Landewée $e^{4,5}$, D. van der Heijde ${ }^{3}$, J. Sieper ${ }^{1}$, M. Rudwaleit ${ }^{6}$, D. Poddubnyy ${ }^{1,7}$. ${ }^{1}$ Charité Universitätsmedizin Berlin, Berlin, Germany; ${ }^{2}$ NOVA Medical School, Universidade Nova de Lisboa, Lisboa, Portugal; ${ }^{3}$ Leiden University Medical Center, Leiden; ${ }^{4}$ Amsterdam Rheumatology and Clinical Immunology Center, Amsterdam; ${ }^{5}$ Zuyderland Medical Center, Heerlen, Netherlands; ${ }^{6}$ Klinikum Bielefeld Rosenhöhe, Bielefeld; ${ }^{7}$ German Rheumatism Research Centre, Berlin, Germany

Background: In patients with axial spondyloarthritis (axSpA), radiographic progression of sacroilitis is relatively slow, with only few predictors identified. Recently, an analysis of data from Ankylosing Spondylitis Assessment Society (ASAS) Cohort, based on local assessment of X-Rays, revealed a surprisingly high rate of regression from radiographic axSpA $(r-a x S p A)$ to non-radiographic axSpA (nr-axSpA).

Objectives: To analyse the rates and predictors for radiographic progression of sacroilitis in patients with axSpA from the ASAS Cohort, based on the central reading of radiographs.

Methods: Altogether 205 patients, who were included in the ASAS Cohort and diagnosed with axSpA by local rheumatologists, with baseline pelvic radiographs available for central reading, were included in the current study. Among them, 106 patients also had a pelvic radiograph at follow up (mean time to follow up $4.4 \pm 0.8$ years). Images were independently assessed by 2 central readers (MP, FP), blinded for the chronology of the radiographs, according to the scoring system of the modified New York criteria (grade 0-4). In case of disagreement in classification (nr-axSpA or r-axSpA), the image was scored by an adjudicator (DP) that defined the final classification. In addition, we calculated a sacroiliitis sum score (0-8) based on scoring results of 2 (3) readers. The primary outcome was the proportion of patients with progression from nr-axSpA to r-axSpA at follow-up. Predictors of progression were investigated in univariable and multivariable logistic regression analyses.

Results: Among 205 patients, 82 (40\%) were classified as $\mathrm{nr}-\mathrm{axSpA}$, and 123 $(60 \%)$ as $\mathrm{r}$-axSpA at baseline. Among 106 patients with available baseline and follow-up radiographs, $49(46,2 \%)$ were classified as $\mathrm{nr}$-axSpA, and $57(53,7 \%)$ as raxSpA at baseline. The agreement between two primary readers in classification (either nr-axSpA or $r$-axSpA) was moderate to substantial ( $\kappa=0.54$ at baseline and 
$\kappa=0.63$ at follow up); between local and central readers - poor to moderate ( $\kappa=0.18$ at baseline and $\kappa=0.58$ at follow up). At follow up, $8(7,5 \%)$ patients progressed from nr-axSpA to AS, while $6(5,7 \%)$ were reclassified from AS to $\mathrm{nr}$ axSpA, resulting in net progression of $1,9 \%$. The sacroiliitis sum score increased in $43(40,6 \%)$ patients, decreased in $21(19,8 \%)$ and did not change in $42(39,6 \%)$. Logistic regression analysis showed an association of active and chronic changes on MRI at baseline, already existing structural damage in the sacroiliac joints (sacroiliitis sum score) at baseline and younger age with higher odds for progression from nr-axSpA to r-axSpA.

Conclusions: There was a low but still detectable progression from nr-axSpA to r-axSpA after up to 5 years of follow-up in the ASAS cohort. Presence of active and chronic changes on MRI, initial structural damage on radiographs, and younger age at baseline were associated with a higher odds for progression from nr-axSpA to r-axSpA.

\section{REFERENCE:}

[1] Sepriano A, et al. Ann Rheum Dis 2016;75:1262-1263.

Acknowledgements: The research was supported by 2016 ASAS Research Internship Grant.

Disclosure of Interest: None declared

DOI: 10.1136/annrheumdis-2018-eular.4498

\section{FRI0176 PERFORMANCE OF SPINAL AND SACROILIAC JOINT MRI FINDINGS IN PATIENTS WITH AXSPA}

S. Lee ${ }^{1,2}$, I. Sari ${ }^{2,3}$, E.S. Tunc ${ }^{2}$, R.D. Inman ${ }^{2,4}$, N. Haroon ${ }^{2,4} .{ }^{1}$ Radiology, Hanyang University Hospital College of Medicine, Seoul, Korea, Republic Of, ${ }^{2}$ Rheumatology, Toronto Western Hospital, University of Toronto, Toronto, Canada; ${ }^{3}$ Rheumatology, Dokuz Eylul University School of Medicine, Izmir, Turkey; ${ }^{4}$ Krembil Research Institute, University Health Network, University of Toronto, Toronto, Canada

Background: Early diagnosis of axial spondyloarthritis (AxSpA) is challenging, particularly in patients with normal sacroiliac joints (SIJs) on radiographs. Currently, magnetic resonance imaging (MRI) is considered as the most sensitive imaging modality for detecting early SpA even before radiographic structural lesions develop. However, there are controversial reports, particularly for the spine, regarding the diagnostic utility of MRI.

Objectives: To determine the diagnostic utility of spine and sacroiliac joint lesions assessed by MRI in patients with ankylosing spondylitis (AS) or non-radiographic AxSpA (nr-AxSpA) compared to chronic mechanical back pain (MBP).

Methods: We included $151 \mathrm{AS}, 110 \mathrm{nr}-\mathrm{AxSpA}$, and $37 \mathrm{MBP}$ patients. Spine and SIJ MRIs were performed in all patients. Two independent readers blinded to clinical details of the patients, scored the MRI images. A third reader participated in disputed cases. On T1 weighted sequences, the following structural changes in SIJs were scored: sclerosis $(\geq 5 \mathrm{~mm})$ and extensive sclerosis $(\geq 10 \mathrm{~mm})$, erosions, ${ }^{1-2}$ extensive erosions $(\geq 3)$, partial or complete fusion, and fat deposition. Presence in at least two consecutive slices was required for erosions and fusion. On STIR sequences, the following inflammatory changes in the SIJs were determined: ASAS-defined bone marrow oedema (BME) and SPARCC SIJ scores. For the spine, the following were defined: fat infiltration at the vertebral corner on $\mathrm{T} 1$ and the number of corner inflammatory lesions (CILs) on STIR. We calculated sensitivity, specificity, and likelihood ratios (LR) of the above-mentioned structural and inflammatory lesions for both AS and nr-AxSpA groups.

Results: There were 298 patients in the study: 151 AS (mean age: 39 (16-77) years; $62.3 \%$ male), $110 \mathrm{nr}-\mathrm{AxSpA}$ (mean age 36 (17-64) years; $45.5 \%$ male), and $37 \mathrm{MBP}$ (mean age 38 (19-59) years; $40.5 \%$ male). Presence of erosion was the most sensitive SIJ-MRI finding for structural lesions in AxSpA (AS 97\%, nrAxSpA 89\%). However specificity of this variable was low (19\%). Evidence of fusion and extensive sclerosis were the most specific SIJ-MRI findings for structural abnormalities with poor sensitivity levels in both groups. On the other hand, presence of extensive erosions showed acceptable sensitivity (78\% and $58 \%$ ) and specificity (62\%) values in both AS and $\mathrm{nr}-\mathrm{AxSpA}$. For inflammatory lesions of SIJ, both ASAS BME and SPARCC $\geq 2$ had similar sensitivity and specificity values in AxSpA. The presence of SIJ fat and evident erosions was associated with a slight increase in Likelihood of AxSpA. Among spinal lesions, spinal fat was the most sensitive finding in AxSpA (67\% and $58 \%$ ) with limited specificity $(40 \%)$. CILs had moderate to high specificity but low sensitivity. All spinal parameters had low positive LRs.
Abstract FRI0176 - Table 1. Performance of different MRI derived SIJ and spine lesions in AxSpA

\begin{tabular}{|c|c|c|c|c|c|c|c|c|}
\hline & \multicolumn{2}{|c|}{\begin{tabular}{|l|} 
Sensitivity $(95 \%$ \\
CI) \\
\end{tabular}} & \multicolumn{2}{|c|}{\begin{tabular}{|l|} 
Specificity (95\%) \\
CI) \\
\end{tabular}} & \multicolumn{2}{|c|}{+ LR (95\% Cl) } & \multicolumn{2}{|c|}{-LR (95\% Cl) } \\
\hline & AS & $\mathrm{Nr}$ & AS & $\mathrm{Nr}$ & AS & $\mathrm{Nr}$ & AS & $\mathrm{Nr}$ \\
\hline \multicolumn{9}{|c|}{\begin{tabular}{|l|} 
Saccro-iliac joint \\
\end{tabular}} \\
\hline Sclerosis & \begin{tabular}{|l|}
51 \\
$(41-$ \\
$61)$ \\
\end{tabular} & $\begin{array}{l}22 \\
(15- \\
31) \\
\end{array}$ & \begin{tabular}{|l|}
$65(48-$ \\
$80)$
\end{tabular} & \begin{tabular}{|l|}
$65(48-$ \\
$80)$
\end{tabular} & $\begin{array}{l}1.5(0.9- \\
2.3)\end{array}$ & \begin{tabular}{|l|}
$0.6(0.4-$ \\
$1.1)$
\end{tabular} & $\begin{array}{l}0.8(0.6- \\
1)\end{array}$ & $\begin{array}{l}1.2(0.9- \\
1.6)\end{array}$ \\
\hline \begin{tabular}{|l|} 
Evident \\
sclerosis
\end{tabular} & \begin{tabular}{|l}
$5(2-$ \\
$11)$ \\
\end{tabular} & $1(0-5)$ & \begin{tabular}{|l}
$100(91-$ \\
$100)$
\end{tabular} & \begin{tabular}{|l|}
$100(91-$ \\
$100)$
\end{tabular} & & & $\begin{array}{l}0.95(0.9- \\
0.99)\end{array}$ & $\begin{array}{l}0.99 \\
(0.97-1) \\
\end{array}$ \\
\hline Fat & \begin{tabular}{|l|}
69 \\
$(61-$ \\
$77)$ \\
\end{tabular} & $\begin{array}{l}36 \\
(27- \\
46)\end{array}$ & \begin{tabular}{|l|}
$73(56-$ \\
$86)$
\end{tabular} & \begin{tabular}{|l}
$73(56-$ \\
$86)$
\end{tabular} & $\begin{array}{l}2.6(1.5- \\
4.4)\end{array}$ & $\begin{array}{l}1.3(0.7- \\
2.4)\end{array}$ & $\begin{array}{l}0.4(0.3- \\
0.6)\end{array}$ & $\begin{array}{l}0.9(0.7- \\
1.1)\end{array}$ \\
\hline Erosion & \begin{tabular}{|l|}
97 \\
$(92-$ \\
$99)$ \\
\end{tabular} & $\begin{array}{l}89 \\
(82- \\
94) \\
\end{array}$ & $\begin{array}{l}1 \\
3 \\
\end{array}$ & \begin{tabular}{|l}
$19(8-$ \\
$35)$
\end{tabular} & $\begin{array}{l}1.2(1- \\
1.4)\end{array}$ & \begin{tabular}{|l|}
$1.1(0.9-$ \\
$1.3)$
\end{tabular} & 6) & $\begin{array}{l}0.6(0.3- \\
1.4)\end{array}$ \\
\hline $\begin{array}{l}\text { Evident } \\
\text { erosion }\end{array}$ & \begin{tabular}{|l|}
78 \\
$(68-$ \\
$85)$ \\
\end{tabular} & $\begin{array}{l}58 \\
(48- \\
67)\end{array}$ & \begin{tabular}{|l|}
$62(45-$ \\
$78)$
\end{tabular} & \begin{tabular}{|l|}
$62(45-$ \\
$78)$
\end{tabular} & \begin{tabular}{|l|}
$2.1(1.3-$ \\
$3.1)$
\end{tabular} & $\begin{array}{l}1.5(1- \\
2.4)\end{array}$ & $\begin{array}{l}0.4(0.2- \\
0.6)\end{array}$ & $\begin{array}{l}0.7(0.5- \\
0.9)\end{array}$ \\
\hline Fusion & \begin{tabular}{|l|}
29 \\
$(22-$ \\
$37)$
\end{tabular} & $0(0-3)$ & \begin{tabular}{|l}
$100(91-$ \\
$100)$
\end{tabular} & \begin{tabular}{|l|}
$100(91-$ \\
$100)$
\end{tabular} & & & $\begin{array}{l}0.7(0.6- \\
0.8)\end{array}$ & $\begin{array}{l}25.3 \\
(25.3- \\
25.3) \\
\end{array}$ \\
\hline ASAS BME & \begin{tabular}{|l|}
51 \\
$(43-$ \\
$59)$
\end{tabular} & $\begin{array}{l}41 \\
(31- \\
51)\end{array}$ & $\begin{array}{l}60(42- \\
75)^{-}\end{array}$ & \begin{tabular}{|l|}
$60(42-$ \\
$75)$
\end{tabular} & $\begin{array}{l}1.3(0.8- \\
1.9)\end{array}$ & $\begin{array}{l}1(0.6- \\
1.6)\end{array}$ & $\begin{array}{l}0.8(0.6- \\
1.1)\end{array}$ & $\begin{array}{l}0.9(0.7- \\
1.4)\end{array}$ \\
\hline $\begin{array}{l}\text { SPARCC } \\
\text { SIJ } \geq 2\end{array}$ & \begin{tabular}{|l|}
51 \\
$(43-$ \\
$59)$ \\
\end{tabular} & $\begin{array}{l}41 \\
(31- \\
51) \\
\end{array}$ & \begin{tabular}{|l|}
$60(42-$ \\
$75)$
\end{tabular} & \begin{tabular}{|l|}
$60(42-$ \\
$75)$
\end{tabular} & $\begin{array}{l}1.3(0.8- \\
1.9)\end{array}$ & $\begin{array}{l}1(0.6- \\
1.6)\end{array}$ & $\begin{array}{l}0.8(0.6- \\
1.1)\end{array}$ & $\begin{array}{l}0.9(0.7- \\
1.4)\end{array}$ \\
\hline \multicolumn{9}{|l|}{ Spine } \\
\hline Spinal fat & \begin{tabular}{|l|}
67 \\
$(59-$ \\
$75)$ \\
\end{tabular} & $\begin{array}{l}58 \\
(48- \\
68) \\
\end{array}$ & \begin{tabular}{|l}
$40(24-$ \\
$58)$
\end{tabular} & $\begin{array}{l}40(24- \\
58)\end{array}$ & $\begin{array}{l}1.1(0.8- \\
1.5)\end{array}$ & \begin{tabular}{|l|}
$0.9(0.7-$ \\
$1.3)$
\end{tabular} & $\begin{array}{l}0.8(0.5- \\
1.3)\end{array}$ & $\begin{array}{l}1.1(0.7- \\
1.7)\end{array}$ \\
\hline \begin{tabular}{|l|}
$\mathrm{CIL}$ \\
presence
\end{tabular} & \begin{tabular}{|l|}
45 \\
$(37-$ \\
$54)$ \\
\end{tabular} & $\begin{array}{l}31 \\
(22- \\
41) \\
\end{array}$ & \begin{tabular}{|l|}
$46(29-$ \\
$63)$
\end{tabular} & \begin{tabular}{|l|}
$46(29-$ \\
$63)$
\end{tabular} & $\begin{array}{l}0.8(0.6- \\
1.2)\end{array}$ & $\begin{array}{l}0.6(0.4- \\
0.9)\end{array}$ & $\begin{array}{l}1.2(0.8- \\
1.8)\end{array}$ & $\begin{array}{l}1.5(1- \\
2.2)\end{array}$ \\
\hline $\begin{array}{l}\text { CIL } \geq 3 \text { vs. } \\
<3\end{array}$ & \begin{tabular}{|l|}
27 \\
$(20-$ \\
$36)$ \\
\end{tabular} & $\begin{array}{l}10(5- \\
18)\end{array}$ & $\begin{array}{l}74(57 \cdot- \\
88)\end{array}$ & $\begin{array}{l}74(57- \\
88)\end{array}$ & $\begin{array}{l}1.1(0.6- \\
2)\end{array}$ & $\begin{array}{l}0.4(0.2- \\
0.9)\end{array}$ & $\begin{array}{l}0.9(0.8- \\
1.2)\end{array}$ & $\begin{array}{l}1.2(0.9- \\
1.5)\end{array}$ \\
\hline $\begin{array}{l}\text { CIL } \geq 5 \text { vs. } \\
<5\end{array}$ & \begin{tabular}{|l|}
19 \\
$(13-$ \\
$26)$ \\
\end{tabular} & $\begin{array}{l}8(4- \\
15)\end{array}$ & \begin{tabular}{|l|}
$80(63-$ \\
$92)$
\end{tabular} & \begin{tabular}{|l|}
$80(63-$ \\
$92)$
\end{tabular} & $\begin{array}{l}0.9(0.4- \\
\text { 2) }\end{array}$ & $\begin{array}{l}0.4(0.2- \\
1)\end{array}$ & $\begin{array}{l}1(0.8- \\
1.2)\end{array}$ & $\begin{array}{l}1.1(0.9- \\
1.4)\end{array}$ \\
\hline
\end{tabular}

Conclusions: Extensive erosions of SIJ showed the most balanced performance in whole spinal MRI assessment. Spinal lesions performed poorly when compared with SIJ findings in discriminating AxSpA from MBP.

Disclosure of Interest: None declared

DOI: 10.1136/annrheumdis-2018-eular.5639

\section{FRI0177 ASSESSING THE VALUE OF WHOLE BODY MAGNETIC RESONANCE IMAGING AS TO CLINICAL EXAMINATION TO PREDICT REMISSION AND RELAPSE IN EARLY PERIPHERAL SPONDYLOARTHRITIS}

T. Renson ${ }^{1}$, P. Carron ${ }^{1}$, S. Krabbe ${ }^{2}$, L. Jans ${ }^{3}$, A.-S. De Craemer ${ }^{1}$, M. de Hooge ${ }^{1}$, P. Jacques ${ }^{1}$, M. Ostergaard ${ }^{2}$, D. Elewaut ${ }^{1}$, F. Van den Bosch ${ }^{1} .{ }^{1}$ Rheumatology, Ghent University Hospital, Ghent, Belgium; ${ }^{2}$ Copenhagen Center for Arthritis Research (COPECARE), Center for Rheumatology and Spine Diseases, Rigshospitalet, Glostrup, Denmark; ${ }^{3}$ Radiology, Ghent University Hospital, Ghent, Belgium

Background: Evaluation of disease activity and treatment response in periphera spondyloarthritis $(\mathrm{pSpA})$ is currently based upon clinical findings, laboratory tests and ultrasound examination. Whole-body magnetic resonance imaging (WB MRI) is a relatively new imaging technique that could offer additional information regarding the inflammatory status of joints, entheses and soft tissues.

Objectives: To determine A) the value of WB MRI, performed at baseline, in relation to clinical remission in $\mathrm{PSpA}$ and $\mathrm{B}$ ) the value of subclinical inflammation, detected by WB MRI, at time of clinical remission in predicting flare after treatment withdrawal in $\mathrm{PSpA}$

Methods: Clinical REmission in peripheral SPondyloArthritis (CRESPA) is a placebo-controlled trial of golimumab treatment in 60 early (symptom duration $<12$ weeks) pSpA patients (pts). All pts underwent a modified WB MRI at baseline and at the time of clinical remission when treatment was withdrawn. The WB MRI was performed by scanning multiple locations individually (using different coils) in order to investigate SpA-specific locations in detail. Several anatomical sites of pelvis and lower limbs were evaluated for bone marrow oedema (BME), synovitis and soft tissue inflammation (STI) by 3 readers, giving a score of 0 (no abnormalities), 1 (mild), 2 (moderate) or 3 (severe). For each site a mean of the scores of the 3 readers was calculated. For each patient at each time point, we calculated a sum score for synovitis, STI and BME separately adjacent to a total sum score. Changes scores are baseline minus remission sum scores. 